prove to be suitable for the requirements of horticultural products of luxury and high value, it may possibly be otherwise with such productions.

The above considerations obviously suggest the question : What is the office of chlorophyll in the processes of vegetation? Is it, as has generally been assumed, confined to effecting, in some way not yet clearly understood, carbon assimilation, and, this done, its function ended; or is it, as Pringsheim has recently suggested, chiefly of avail in protecting the subjacent cells and their contents from those rays of light which would be adverse to the secondary processes which have been distinguished as growth?

Appropriate as it would seem that I should attempt to lay before you a résumé of results bearing upon the points herein involved, so numerous and so varied have been the investigations which have been undertaken on the several branches of the question in recent years, that adequately to discuss them would occupy the whole time and space at my disposal. I must therefore be content thus to direct attention to the subject, and pass on to other points.

(To be continued.)

\section{THE BRITISH ASSOCIATION REPORTS}

Report on the Tertiary Flora of the Basalts of the North of Ireland, by Mr. W. H. Baily.-Described the plants of Miocene deposits, consisting of variegated marls, resting on a leaf-bed near Glenarm. Amongst the plants were Sequoia couttsia, $S$. lyelli, Fagus deucalium, Nyssa ornithobroma, Aralis brozenia, Fraxinus guillelma. These and others have been drawn and described.

Report on the Viviparous Nature of the Ichthyosauri, by Prof. H. C. Seeley.-Dr. Channen Pierce had formerly described a specimen of Ichthyosaurus in the Museum at Bristol which he considered contains a foetus in the act of coming into the world, which view is supported by Prof. Seeley, who showed, reasoning by the analogy of the stomach of a crocodile, it was impossible that this animal could have swallowed a smaller ichthyosaurus, and its remains been retained in the stomach in a perfect fform, and alludes to the spiral structure of the coprolite, pointing to a small intestine, and thought it is impossible that the animal could have passed through them in the process of digestion; and alluded to the fact that all German specimens show the head of the smaller projecting towards the tail of the larger, though the reverse is the case in a specimen at Madrid. But in Tübingen the most perfect specimens occur, in which the smaller animals are found lying completely preserved between the ribs of the parent animal; though, he suggests, in all cases viviparous characters may not have obtained in all forms of ichthyosauri.

The Sixth Report of the Underground Water Committee was read by Mr. De Rance, who pointediout that the watershed separating the basins of the Thames and. Eastern Counties from those of the Humber and the Severn also divides the area of heaviest rainfall on the Palæozoic rocks, which are nearly all impermeable, from those of Secondary age, receiving a rainfall of about 30 inches. West of this line, with the exception of the Trias, no Secondary rocks occur. In Lancashire, Cheshire, and the Midlands the Triassic Sandstones absorb about one-third of the rainfall, giving a daily average of 400,000 gallons to each square mile of country : wells in these rocks are capable of drawing on several square miles, and in suitable situations of yielding from 2 to 3 million gallons per day. The discovery of the Manchester coalfield beds at Winwick, near Warrington, under the New Red Sand. stone, at a depth of only 340 feet, was described. He referred to the position of the New Red boring at Bootle, for the Liverpool Corporation water supply, as very badly chosen, being close to one of the existing wells. He then showed the gradual attenuation in thickness of the Bunter Sandstones, in a southerly direction, against the old Palacozoic axis, ranging from the Belgian coalfield to the Mendips.

Report on the Present State of our Inowledge of the Crustacea, by C. Spence Bate, F.R.S. - This is Part v. of the Report, and deals with the subjects of fecundation, respiration, and the green gland.
SECTION A.-MAThematical And Physical

Improved Apparatus for the Objective Estimation of Astigmatism, by Tempest Anderson, M.D., B.Sc.-Astigmatism has been defined as that condition of the eye in which refraction is unequal in the different meridians. In order to obtain suitable spectacles for correcting this defect, it is necessary to know accurately the focal adjustment of the meridians of maximum and minimum curvature, whence the focal lengths of glasses, generally either cylindrical or cylindrical on one side and spherical on the other, are readily calculated. Many plans have been adopted for determining this; some subjective, depending on observations made by the eye itself, and generally using a point of light or a series of radiating lines as an object. From their appearances when viewed at different distances, and with lenses of different powers, the focal adjustment of the different meridians is at last obtained.

The advantage of this group of methods is their theoretical delicacy, as they work by judging of the perfection of certain images refracted on the retina in a manner not very dissimilar to that in which they are usually formed; the practical disadvantage, that accurate observations are required from one who has never been accustomed to make them. Hence objective methods have been introduced. Their advantages are, substituting trained for untrained observation. Their disadvantages-

r. The vessels of the retina and the optic nerves, which are mostly employed as objects, are seldom in exactly the position desirable for estimating the refraction in different meridians, and are often at a different distance from the optical system of the eye from that at which the sensitive layer of the retina lies.

2. They mostly require the optical defects, if any, and the accommodation of the observing eye to be taken into account and allowed for, thus introducing risk of error.

In the author's two instruments, an image of a suitable object thrown on the retina of the observed eye, is used as an object by the observer, with the following advantages :-

I. The patient's sensations may be entirely disregarded, or only used as confirmatory.

2. The image used is necessarily at the retina, and not before or behind it.

3. The accommodation or any defects in the refraction of the observer's eye does not enter into the result, as the only function of this eye is to observe the formation of the image on the retina.

In the first plan a lamp $l$ is provided with a condensing lens $c$, and a series of radiating wires $w$ (supposed to be seen edgeways in the figure), thus giving a bright field with black lines on it.

The whole slides on a graduated bar $C$, at the other end of which is a convex lens $y(4$ and Io dioptrics are the most convenient powers, i.e. 10 and 4 inch focus). Close to the lens, and at an angle of $45^{\circ}$ to its axis, is a plane mirror $(\mathrm{m})$, which reflects the rays at right angles to their former path. The instrument is to be held so that this pencil of rays enters the observed eyc, and when the wire screen is at the proper distance, an image of it is formed on the retina. The mirror has the centre left unsilvered, as in an ordinary ophthalmoscope, and has a disk of correcting lenses behind it, to render the retina, and the image on it, visible by the direct method. The ob. served eye should have its accommodation relaxed by atropine

The bar is so graduated that when an image of the whole or part of the screen is sharp on the retina, the figure opposite the screen expresses the refractive error of the meridian by which the image is produced. Hence if the image of the whole screen is seen to be equally sharp, the eye is known to be not astigmatic, and the gradustion given the number of dioptrics by which it is myopic or hypermetropic. If the lines be not all sharp at once, then the most distant point at which a distinct image of any of the wires is formed on the retina gives the refractive crror of the meridian of minimum refraction (expressed in dioptrics), and the point at which the line at right angles to this is best defincd, gives that of the meridian of maximum refraction. The least of these gives the spherical element of the correcting lens required for distant objects, and the difference between the two gives that of the cylindrical part. The meridian of maximum refraction is that in which the line is visible when the wires are at the greatest distance.

In the second plan the lamp, $l$, condensing lens, $c$, and wire screen, $w$, are similar, and only differ in size, the front lens, $y$, and mirror, $m$, arc also similar, but the lamp and wires are permanently fixed by a tube, so that the wires are accurately in 
the principal focus of the front lens, $y$. By this means the rays from the wires (or rather from the interval between them), after refraction through the lens and reflection by the mirror, are parallel. If received by an eye which is emmetropic, and with its accommodation relaxed, an image of the wires is formed on the retina. The light radiating from the image passes out through the optical system of the eye; is rendered parallel and able to form an accurate image on the retina of an emmetropic eye observing through the hole in the mirror.

If the observed eye be not emmetropic, it is only necessary to introduce lenses of different powers close in front of it, so as to correct the rays both entering and leaving the eye. If the refraction be the same in all meridians, the image of all the wires is sharp with the same lens, and this lens is the one required to correct the ametropia. If any astigmatism exists, different lenses are required for rendering the images of the different wires sharp.

The strongest and weakest of these are the measures of the errors of refraction of the two principal meridians, and the difference of their numbers of dioptrics gives the cylindrical element of the correcting glass required.

In this form of apparatus a disc of correcting lenses behind the mirror is not required, as the single correcting lens near the observed eye corrects the rays both entering and leaving the eye.

For rapidly finding the proper lens a disk of lenses is used,

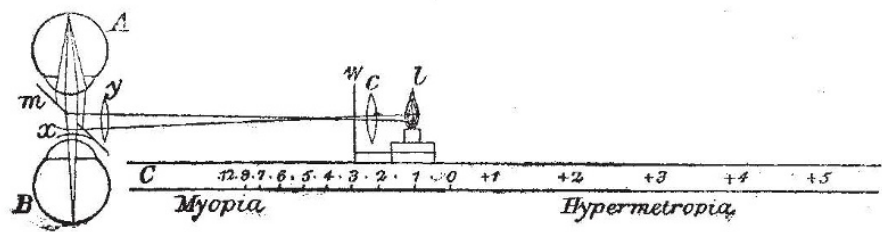

each a centimetre in diameter, and with intervals of one dioptric; a smaller disc is attached containing the quarter dioptrics, so that by their combination intervals of one quarter of a dioptric can be read-a degree of accuracy greater than the estimation is generally susceptible of.

The proper lens being calculated, its spherical and cylindrical elements are combined and put together before the eye. It it be the correct one, all the lines are seen sharp at the same time; if not, further examination is made.

The principal advantage of the first plan is that the adjnstment, being made by the motion of the wire screen, is continuous, and correcting lenses are not required for measuring the refraction, but only for rendering the retinal image visible; its disadvanatge that, as the rays are not parallel as they pass from the front lens, past the mirror to the eye, it is necessary for the apparatus to be very near, and at a determinate distance from the observed eye, otherwise the readings of the scale are vitiated. This, however, is not a serious objection.

In the second plan the rays in the corresponding position are parallel, and the instrument can be held at any convenient distance, say one or two feet from the observed eye, and the observer can get a view of the cornea at the same time as he views the image, so that he can estimate the refraction at different points of the cornea.

It is hoped that this may eventually lead to the determination of the refraction at different parts of conical cornea and other eyes with irregular astigmatism, and the application of suitable lenses to them.

Since writing the above, I find mention of an instrument by Coccius Stimmel, with an optical arrangement on the same plan as my second, but I have not heard of its being in use in this country.

The makers are T. Cook and Sons, York.

\section{SECTION D.-BIOLOGY}

After Dr. Sclater hadread report of Socotra Committee, Dr. J. B. Balfour gave a very interesting account of his visit to the island. The zoological and botanical collections have not yet been examined by specialists, but are expected to yield results of great interest. As not nearly sufficient time had been allowed for a complete exploration of the island, which is almost entirely unknown to Europeans, Dr. Balfour hoped that another similar expeditionwould be organised; but in that case it should be earlier in the season than the last, which was in the island during February and the early part of March. During the latter part of the time the heat was too great for it to be possible to do anything in the middle of the day. Dr. Sclater mentioned that the ornithological collection indicated distinct African affinities.

Further Remarks on the Mollusca of the Mediterranean, by J. Gwyn Jeftreys, LL.D., F.R.S.-This is a supplement to a paper by the anthor, which was published in the Report of the Association for 1878. Since that time many of the species which were supposed to be exclusively Mediterranean have been discovered in the North Atlantic. The number of such Mediterranean species, which were given in the former paper, was 222 .
In the present paper $4^{\mathrm{I}}$ of those species are enumerated as also Atlantic, thus reducing the number of exclusively Mediterranean species to I8r, and it was remarked that the Atlantic nudibranchs and Cephalopods had not been completely worked out, these anounting to 58 , and being included in the above residue of $\mathrm{r} 8 \mathrm{r}$.

On the Migration of Birds, and Messrs. Brown and Cor. deaux's Method of obtaining Systematic Observations of the same at Lighthouses and Lightships, by Prof. Newton, M.A., F.R.S. (Abstract).-Citing a passage from an article by the Duke of Argyll (Contemp. Rev., July, 188o, p. 1), the author met with a direct denial the Duke's assertion that of "the army of the birds" it might be said that "it cometh not with observation," pointing out that all we know of the migration of birds arises from observation, and all we do not know from the want of it, remarking "also that if it were not f or observation we should not know that birds migrate at all, and inquiring whether it is not by renewed observation alone that we can hope to know more of their migratory movements. The author then proceeded to describe briefly the nocturnal passage of migratory birds as noticed by himself at Cambridge for the past seventeen years, and urged the importance of simlar. but more systematic observations being made at other statioins Remarking upon the especial advantages of lighthouses and light. ships for this purpose, he recounted the successful attempt made in the autumn of 1879 , with the sanction of the Trinity House authorities and the Commissioners of Northern Lights, by $\mathrm{Mr}$. Harvie Brown and Mr. Cordeaux, to obtain a series of observations from the lighthouses and lightships on the coast of Scotland and the east coast of England, the results of which were embodied in a Report (noticed in NATURE, vol. xxii. p. 25), and showed that returns were obtained from nearly two-thirds of the English stations, and as regards the Scottish stations, from about two thirds on the west and one-half on the east coast, thus proving the intelligent interest taken by the men employed in the inquiry. This single Report naturally did not throw any new light on the subject, but it would be contrary to all experience if a series of such reports would not, and he therefore strongly urged the Association to countenance the renewed attempts which Messrs. Brown and Cordeaux were making, and to encourage with its approval them and their fellow-workers, the men of the lighthouses and lightships, who could best answer the question whether knowledge of "the army of the birds" and its movements "cometh not with observation."

On Anthropological Colour-Phenomena in Belgium and elsewhere, by J. Beddoe, M.D., F.R.S.-In Germany, Switzerland, and Belgium, through Governmental assistance, the colours of the eyes and hair of all the children in the primary schools have been observed and tabulated. The writer is very desirous that our own officials should lend similar assistance to the Anthropometric Committee of this Association. The results hitherto obtained have been of considerable importance, and those for Belgium are well shown in the monograph and maps of Prof. Vanderkindere. These bring out a remarkable contrast between the Flemish and the Walloon provinces of Belgium, and tend strongly to prove the persistently hereditary character of even such physical characters as the colour of the hair and the iris. 
Pocket Registrator for Anthropological Purposes, by Francis Galton, M.A., F.R.S. - The author exhibited a small instrument a quarter of an inch thick, four inches long and one and three quarters wide, furnished with five stops, each communicating by a ratchet with a separate index arm that moves round its own dial-plate. The registrator may be grasped and held unseen in either hand with a separate finger over each stop. When any finger is pressed on the stop below it, the corresponding index arm moves forward one step. Guides are placed between the stops to insure the fingers occupying their proper positions when the instrument is seized and used in the pocket, or when it is slipped inside a loose glove or other cover. It is possible by its means to take anthropological statistics of any kind among crowds of people without exciting observation, which it is otherwise exceedingly difficult to do. The statistics may be grouped under any number of headings not exceeding five. If it should ever be thought worth while to use a registrator in each hand, ten headings could be employed. The instrument that was exhibited worked well, but it was the first of its kind, and might be improved. It was made by $\mathrm{Mr}$. Hawkesley, surgica linstrument maker, 300, Oxford Street, London. The author also drew attention to the ease with which registers may be kept by pricking holes in paper in different compartments with a fine needle. A great many holes may be pricked at haphazard close together, without their rumning into one another or otherwise making it difficult to count them afterwards. The mark is indelible, and any scrap of paper suffices. The needle ought to project a very short way out of its wooden holder, just enough to perforate the paper, but not more. It can then be freely used without pricking the fingers. This method, however, requires two hands, and its use excites nearly as much observation as that of a pencil.

Dr. Phené, F.S.A, F.R.G.S., read a paper On the Retention of Ancient and Prehistoric Customs in the Pyrenecs. He said he could now repeat more confidently the peculiar features which indicate beyond question that the customs of the Gallic population of the South of France agreed, so far as they might judge from their lithic monuments, with those who came farther north and settled in Britain. On the crests and sides of the mountains on both sides of the Pyrenees, i.e. in Spain and France, are found sepulchral arrangements of stones somewhat different to any distinctly recorded amongst our antiquities, These consist of a number of circles adjoining each other; in the centre of each is a cist with an urn, having burnt bones, and the form of the circle is that of a wavy or serpentine cross. The quaint old customs of early Celtic life are kept ap all along the Pyrenees, but not in the towns, in the plains, or champagne country. One of these, which he described last year as still existing in Brittany, that of a wooden tally, in lien of a bill or account, on which the baker marked by notches the number of loaves he supplied, and which attracted the attention of the President of the section last year, was also existent in the Pyrenees. He purchased a baker's bill at Perpignan a few months ago, and though not so rustic as that of Brittany, it approached more to our old Exchequer tally, and to the Welsh stick of writing described in "Bardas," as well as to some elaborate and really wonderful calendars, still to be seen in the Cheetham Museum at Manchester, than to the rustic tally of Brittany. On crossing into Spain and prosecuting inquiries, he found the serpent or dragon emblem everywhere prominent, and even learned that the Tarasque, the ceremony of which is performed at Tarascon, in Provence, was a well-known dragon with the Spanish people. He was told that, though used as a popular diversion at fêtes, it had always a religious meaning. At Luchon living serpents are consumed in the flames. The youths of the village had miniature cloven pines which they burn. These they brandish while flaming, in serpentine curves, and cry loudly, "hilla-hilla"-pronounced "ella." But the Basque $l$ often stands for $\%$, and if we used it here, we had the old classic cry of the Bacchanals, who with serpents in their hands rushed about wildly crying "Eva, eva." The place where these cries are mostly practised has most remarkable sculptures of serpents. After the burning of the pine a rush is made by the more powerful, and the burning embers carried off in their hands regardless of pain. Pieces are then distributed to every household, and kept religiously during the year, as was the custom with the ancient Britons.

Mr. Thomas Plunkett contributed a paper On an Ancient Settlement found about Trventy-one Feet beneath the Surface of the Peat in the Coal Bog near Bohoe, County Fermanagh.-
This interesting discovery consisted of the remains of two log huts found in a primitive crannage. Flint implements, handmade pottery, and other objects, but no metal of any kind, were found in connection with the huts, which, the author was of opinion, were formed before the age of bog pine, as no pine occurred below the level of the site on which the huts stood. The fact that twenty-one feet of dark, compact peat had grown since the structures were formed was substantial evidence of their great antiquity.

Prof. Dawkins remarked that this discovery did not stand alone, but in connection with others showed that in various parts of Ireland we might look for $\log$ houses in this way, pointing back to a series of ancient wooden houses which belonged to the Neolithic people.

Prof. Rolleston read papers On the Structure of Round and Long Barrows, his remarks being illustrated by a number of diagrams. Premising that one of his objects was to preserve barrows from being spoilt, and thus to prevent the destruction of certain links in the history of our species, he described the construction of barrows which he had explored, and urged the abso. lute necessity of very great care being exercised in such exploration. Speaking of urn burials in round barrows, the Professor briefly referred to the question of the cremation of bodies, and the idea of it. Why did the people burn their dead? He believed the idea was this--that all savage races, when they had to deal with an enemy, were exceedingly prone to wreak certain ignominies on dead bodies. Burning the bodies put it right out of the power of the enemy to do this, and the urn enabled people to carry away their friends who were so burnt. In time of pestilence it $b$ came actually necessary for sanitary considerations to burn the dead, and it was only in time of plague or war that we found that cremation or burning became the order of the day, and that was readily explicable by the fact that men always did what they could on the principle of least action, because burning was a troublesome process. Any universality of burning was explained by the fact that ancient history was simply one great catalogue of plague and pestilence and war and the like. Of course he was an enemy to cremation, because it did a great deal of harm, preventing us from knowing what sort of people our predecessors were. Prof. Rolleston chronicled the finding in a barrow of the Bronze period of a man laid out at full length, the general rule being that of burial in a contracted position. As regarded the date to be assigned to these things, he might give it as his opinion that no Roman ever used a bronze sword, nor crossed swords with an enemy using a sword of that material. As regarded the long barrows, that mode of burial stretched all the way from Wales to the Orkneys, and in them was found not a scrap of metal. His opinion was that the idea of the construction of these barrows was taken from limestone mountain headlands projecting into the sea, such as might be seen by a little trip in their immediate locality. The men lived in caves, and the idea for the place of burial was taken from the place of living, it being often found that a man made the house in which he lived his burial-place.

A short discussion having taken place on Prof. Rolleston's paper, Dr. Schaafhausen, of Bonn, exhibited the Neanderthal skull which was found in 1857 , and which, he submitted, was not the skull of an idiot, but of a man of the lowcst development. Prof. Rolleston agreed that the ran whose skull it was was not an idiot, and said that the abnormal development in connection with it consisted in the frontal ridges.

A paper by Miss A. W. Buckland On Surgery and Superstition in Neolithic Times was read. Miss Buckland said it had been proved by the late Dr. Broca that the system of trepanning prevailed in Neolithic times, and the paper was to show the extent of the practice, the superstitions associated with it, and its connection with the use of cranial amulets. The surgical operation known as trepanning consisted in making an opening in the skull (chiefly of infants) in order to cure them of certain internal maladies, and the individuals who survived were considered to be endowed with properties of a mystic character. Dr. Broca stated that the custom died out with the introduction of bronze. Miss Buckland said the custom still existed among the South Sea Islanders, the Kabyles of Algeria, and the mountaineers of Montenegro. The other papers read in this department were: On Bushmen Crania, by Prof. Rolleston; The Salting Mounds of Essex, by Mr. H. Stopes; The Hittites, by Mr. W. St. C. Boscawen; Further Researches on the Prehistoric Relations of the Babylonian, Chinese, and Eoybtian Characters, and Languzages, and Culture, by Mr. Iyde Clarke; 
The Mountain Lapps, by Lient. G. T. Temple; Note on a Chilian Tumulus, by Mr. J. II. Madge; and India the Home of Gunpowder on Philological Evidence, by Dr. Gustav Oppert.

\section{SECTION E.-GEOgraphy.}

The President read some letters of a very interesting character from Mr. Joseph Thomson, received by the Royal Geographical Society's East African Expedition. The following are passages from this correspondence :-

$$
\text { "Karema, or Musamwira, Lake Tanganyika, }
$$

"I have failed in my attempt to reach Jendwe by way of the Lukuga and Kabuire. I left Kasenga (or Mtowa) on January 19, with all the confidence of a young lion which had not yet known a reverse, and six weeks after I returned to the same place as meek as a lamb. From the very first I had great difficulties with the men, as they believed I was taking them to Nanguema, where they would be eaten up. They tried every means in their power to throw obstacles in my way and retard my movements, two of them deserting near Meketo, and the others threatening to do the same. For six days I continued my cour: e along the Lukuga, in spite of their opposition, but I was then obliged to give in. It flows in a general west-north-west direction to that place, and then about west into the great westerly bend of the Congo, all the way through a most charming valley, with hills rising from 600 to 2,000 feet in height. Above the lake the current is extremely rapid, and quite nunavigable for boats or canoes of any description, owing to the rapids and rocks. From Makalumbi I crossed the Iuknga into Urua, and struck south-west for the town of Kiyombo, who is the chief of all the Warna on the eastern side of the Congo." "We reached Mtowa on March Io, destitute of almost everything. To my delight, however, I heard that $\mathrm{Mr}$. Hore was expected every day on his way by canoe to the south end of the lake. On the $23^{\text {rd }}$ we started, crossed the lake to Kungwe, and reached Karewa on the night of the 26 th. As we neared the shore, we were hailed by the jolly voice of Capt. Carter, whom we found gun in hand and bursting with stories of his wonderful adventures in sport and war, keeping us fixed on our seats all night in his tent as he launched them forth. We went over to visit the Belgian international party at their temporary quarters to-day. Capt. Carter had his elephant ready to take us :across the marsh. Karema is one of the most extraordinary places for a station that could be found on the lake - a wide expanse of marsh, a small village, no shelter for boats, only shallow water dotted with stumps of rock, no room to be got, and natives hostile; far from any line of trade. The party have commenced building forts and walls, digging ditches in regular military fashion. At table there sat down an Englishman, an Irishman, a Scotchman, a Frenchman, a Belgian, and a German, representing five expeditions, and you will doubtless be pleased to learn that of all these (thanks to yourself) the Scotchman, though the smallest, and having to travel through entirely new country, had been the most successful of all. After leaving Karema we had a moderately good voyage across the lake to Jendwe, at which we arrived on April 7." "Passing round the south end of Tanganyika along the shore as far as the mouth of the Kilambo, then striking about N.N.E. through Ulungu and Fipa, we reached by easy ascents the town of Kapufi, situated in lat. $8^{\circ} \mathrm{S}$. and long. $32^{\circ} 25^{\prime} \mathrm{E}$. Best of all, however, while at this place, I had the honour to settle the problem of Lake Hikwa, or rather Likwa, and give it some shape and place in our maps. It has run itself in the hearsay accounts of successive travellers into various protoplasmic shapes, and, will-o'-the-wisp like, danced about on the map to the tunes of various geographers. I, of course, saw only a part of it, but from all I could gather it must be from sixty to seventy miles in length and fifteen to twenty in breadth. It lies two days east of Makapuli, in a deep depres. sion of the Lambalamfipa Mountains. A large river called the Mkafa, which rises in Kawendi, and which by its tributaries drains the greater part of Khonongo and Fipa and all Mpimbwe, falls into it. I can almost say with certainty that it has no outlet, certainly not any towards the west. The Kilambo rises near Kapufi. I was surprised and pleased to find that my bearings and estimated distances, as laid down on my sketch map every two days, had actually brought me within one or two miles of Tabora as laid down by Speke and Cameron. I can hardly, however, call it anything but a curious coincidence."
The colleagues of Major Serpa Pinto in the Portuguese expedition to West Central Africa (Capt. H. Capellu and Lieut. R. Ivens) were warmly reçived in the Geographical Section. They had thoroughly explored the elevated watersheds of Bihe. Major Serpa Pinto went on his famous journey towards Mozam bique, and Messrs. Capello and Ivens struck towards the northeast, nearly reaching Congo. They descended the great tributary of the Congo till they reached more than $6 \frac{1}{4}^{\circ} \mathrm{S}$. lat., where there is a great forest-belt inhabited by tribes of hostile and ferocious negroes. Not far from the shores of this river there dwells one of the most powerful potentates of this part of Africa, but the country is very unhealthy, and the people inferior in every respect to the Highlanders of Bihe. The President and Sir Henry Barkly and other members of the Section congratulated the Portuguese on their renewed geographical enterprise, and acknowledged in particular the indebtedness of geography to the explorers, from one of whom (Lieut. Ivens) the Section had heard an account of their travels.

Mr. Lawrence Oliphant described the results of his recent travels east of the Jordan, and particularly of his visits to labyrinthine subterranean cities. The object of his visit was described as that of selecting country for colonisation, and he reported that there was much pasture, wooded, and arable land capable of the highest degree of development.

Mr. Butler proposed a scheme for supplying pictorial aid to geographical teaching. The travels of a Jersey gentleman, $\mathrm{Mr}$. W. Mesny (who was so useful to Capt. Gill in his journey across China), up the Canton River, and Mr. Carl Bock's account of his exploring expedition in Borneo for the Dutch-Indian Government, were other subjects before this Section.

Col. Tanner read some interesting Notes on the Dara Nur, Northern Afghanistan, and its Inhabitants. He described the inhabitants of the Dara Nur valley as differing little in appearance from the Afghans. "Their features are softer, and they are more trustworthy and less given to fanalical outbreaks than the Pathans, and though they continually fight among themselves, they have never given us trouble in Afghanistan. The forts of the Dara Nur were similar to those of the Jellalabad plain, and the interior arrangement the same. The people still retain the custom of sitting on stools, and, as a rule, are not at home when squatting on the ground. Among the Kohistanis and Kafirs stools are in general use." Then followed a description of a people residing in the upper part of this valley called the Chuganis. "They live in the highest habitable parts of the Kund range. East and west they are hedged in by the powerful race of Safis, their hereditary enemies, and peace is seldom known between them. The appearance of a Chugani is quite different from that of an Afghan or a Dar Nuri. He is shorter in stature, and has more pleasing features. The Chuganis are the only Mohammedans I know who allow to the women perfect and unconstrained freedom. Young and old, married and single, they go about as they do in Europe, without any of the false modesty of the ordinary Indian and Afghan females. The wife of my host and her daughters used to ask me every morning how I fared, and became at last quite friendly. In one other place only have I been allowed to converse without restraint with the women, and that was in a remote and wild part of the Brahti country, where mollahs are unknown and the tenets of the Prophet but imperfectly understood. The Chugani young lady takes a pride in her appearance. .... The town of Aret is one of the most remarkable collections of houses I have ever seen. It is built on the face of a very steep slope, and the houses, of which there must be 600 , are ranged in terraces one above another. From the roof of one of the lower ones I gazed with astonishment at a vast amphitheatre of carved wood, there being in sight thousands of carved verandal. posts, and tens of thousands of carved panels, with which the upper storeys of the houses are constructed. These panels, which are arranged similarly to the shutters of Indian shops, are ornamented with every conceivable variety of carved patterns. The carving completely covered the woodwork of the upper storey of every house. . . . . From one of the numerous native visitors I heard much about the Sanu Kafirs, with whom the Kordar Chuganis carry on much traffic. The little-known people whom the Afghans are pleased to call Kafirs are now confined to a tract bounded on the north and north. west by the Hindu-Kush, on the east by the Hindu range, and on the south and south-west by the Kund range, and by the Laghman. The tribes are very numerous, and speak many different languages. The great tribe of 
the Katawas live in a country sufficiently open and level to admit of their becoming good horsemen. The Samus number some five or six hundred families, and live at the upper end of the Pech Dara. They are described as a merry people, given much to dancing, singing, music, and wine-bibbing. At their meals they sit in a circle and eat sedately, and with dignity, the silver wine goblet placed in a stand conveniently near being passed round the company from time to time. They shake hands in the English fashion. The women tie up the hair with a silver band. Long massive silver chains presented by the tribe are worn over the shoulders of warriors who have deserved well of their clan. Their religion is simple; the men invole the aid of their gods in battle, vowing offerings if they are successful in the fight, and these offerings are stored up in the temples. The Kafirs are being continually encroached upon by the surrounding Afghans. Raids on a large scale are constantly made into their mountain valleys, partly to secure the women as slaves, and partly by fanatical Mohammedans on religious grounds."

$A$ Visit to the Galapagos Islands in H.M.S. "Triumph," I880, by Capt. Markham. - Capt. Markham gives an account of a visit he paid to the Galapagos Islands on board H.M.S. Triumph, in the beginning of the present year. The Admiralty chart, compiled from a rough survey made nearly half a century ago, is not very raccurate, so that it was not safe for a large ironclad like the Trizmph to extend the cruise in the numerous channels between the islands. Her visit was therefore confined to I'ost Office Bay in Charles Island, and the paper records the observations that werc madc during several inland excursions.

The Galapagos Islands, being 600 miles from any other land, have a peculiar fauna, and Capt. Markham devoted all the time at his command to the collection of birds, skins, insccts, and shells. These specimens have been placed in the hands of $\mathrm{Mr}$. Salvin, and it is anticipated that they will form an addition to our knowledge of the natural history of this isolated archipelago.

In our report of Mr. Weldon's paper, read before the Chemical Section of the British Association, it is stated :- "Molecular heats of formation of elements of the same group divided by the atomic volumes of the electro-negative elements give numbers either irlentical with, or bearing some simple relation to, each other." This should rear :- "Molecular heats of formation of compounds of positive elements of the same group with the same electro-negative element, divided by the atomic volumes of the positive elements, give quotients either identical with, or bearing some simple relation to, each other. Thus :-

$$
\begin{aligned}
& \text { Mol. heat of formation of Mol, heat of formation of } \\
& \mathrm{PbCl}_{2}, \mathrm{PbBr}_{2}, \mathrm{PbI}_{2}, \mathrm{PbO} ; \mathrm{Cu}_{2} \mathrm{Cl}_{2}, \mathrm{Cu}_{2} \mathrm{Br}_{2}, \mathrm{Cu}_{2} \mathrm{I}_{2} \text {, and } \mathrm{Cu}_{2} \mathrm{O} \\
& \text { Atomic volume of } \mathrm{Pb} \text { : Atomic volume of } \mathrm{Cu}
\end{aligned}
$$$$
:: \text { I : I }
$$

\section{SCIENTIFIC SERIALS}

Rivista Scientifico-Industriale, No, 13, July r 5,-Water in alcoholic fermentation, by Prof. Pasqualis.-On animals which exhale an odour of musk. - New observations and note on Croolies' apparatus, by Prof. Serpieri.-On automatic geodetic instruments, by Prof. Vecchi

American Fournal of Science, July.-Contributions to meteoro$\log$, by E. Loomis.-Geological relations of the limestone belts of Westchester county, New York, by J. D. Dana,-Observations on Mount Etna, by S. P. Langley.-Antiquity of certain subordinate types of freshwater and land rnollusca, by C. A. White.-Description of a new position micrometer, by $\mathrm{L}$. Waldo. -Boltzman's method for determining the velocity of an electric current, by E. II. Hall, $\rightarrow$ Mineralogical notices, by C. U. Shepard. - Im: rovement in the Sprengel pump, by O. N. Rood.

\section{SOCIETIES ANI ACADEMIES PARIS}

Academy of Sciences, September 6.-M. Wurtz in the chair.-The following papers were read :-Researches on basic salts and on atakamite, by M. Berthelot.-Contributions to the history of ethers, by the same.-On the etiology of anthracoid affections, by $M$. Pasteur. He cites some facts in support of his theory. On a spot in a meadow where an anthracoid cow had been buried in 1878 , a small enclosure was formed, and four sheep put in it ; in another enclosure, a short way off $(3 \mathrm{~m}$. or $4 \mathrm{~m}$.$) , four other sheep. In seven days one of the former$ set died of the disease; none of the latter set were affected. (Germs of charbon had been found on the yround over the buried cow, but not a few metres off.) M. Pasteur differs from M. Toussaint's opinion that acute septicæmia is identical with chicken cholera.-M. Bonley gave some account of recent experiments of M. Toussaint, apparently showing the efficacy of preventive inoculation of sheep and rabbits against charbon by his method. He hopes that once preventive inoculation has become practical, it will be possible to make, not races, but generations, refractory to the disease, by inoculating the mothers during the last period of gestation.-Planet (217), discovered by M. Coggia at the Observatory of Marseilles, on August 30, I88o, by M. Stephan.-On the part taken by Claude Jouffroy in the history of the applications of steam, by M. de Lesseps. This refers to a regret expressed by the granddaughter of the inventor that M. de Lesseps had not, at the inauguration of Papin's statue, recalled the services of Jouffroy, who, in 1783 , invented the pyroscaph, which steamed on the Saone sixteen months, making two leagues per hour. M. de Lesseps had thought it his rôle only to recall the inventions anterior to Papin, and those of Papin himself.-The enemies of the gallicolar phylloxera, by M. Coste.-Observations of solar protuberances, facula, and spots, during the first half of 1880 , by $P$. Tacchini, The increase of solar activity is evident. The observations as to distribution agree well with those of previous quarters. The maximum of frequence of groups of facule is nearer the equator than that of protuberances. There are more groups of faculp in the north than in the south hemisphere (nearly double the number); the protuberances are equally distributed in the two hemispheres. The maximum of frequence of spots and faculæ is produced in the same zones in the two hemispheres.-On the law of magnetoelectric machines, by M. Joubert.-On the variations of fixed points in mercury thermometers, and on the means of taking account of them in estimation of temperatures, by $M$. Pernet. He confirms M. Crafts' views, and gives a formula for calculating the minima of zero, \&c. He states that he can restrict to 1 of a degree for several hours the variations of zero in a thermo. meter whose zero has undergone a depression of $0^{\circ} .8 \mathrm{C}$. after determination of the $100^{\circ}$ point.-On borodecitungrtic acid and its salts of sodium, by M. Klein.-Inoculation of the rabbit with glanders; destruction of the virulent activity of the matter of glanders by desiccation; transmission of glanders by inocula. tion with the saliva, by M. Galtier. This points to the possibility of healthy cavalry horses being contaminated by drinking from the same trough with horses in which the disease is present in a latent state. M. Larrey called attention to a disease that was once very common in the army, where soldiers ate out of a common porringer; it is an inflammatory and ulcerous affection of the mouth. The disease disappeared after the practice was given up in 1852 .

\section{CONTENTS}

PAGR

The Toothed Brris of Kansas

THE THEORY OT DETERMINANTS

LETTERS TO TIIE EUITOK:-

The Stone in the Nest of the Swallow.-CHatre

A Peat Bed in the Drift of Oldham - TAs N

of South-tastern

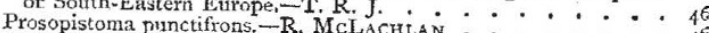

Mosquitces.-M. A. VHERER

Hardening of Steel.-T. W, GritAy : $: \therefore: \therefore: \therefore: 460$

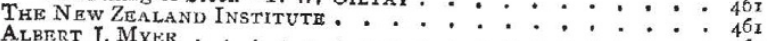

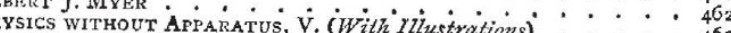

Notes .

OUr Astronomical Columa :-

Schaberle's Comet (480, April 6 ) : . . ${ }^{466}$

Swift's New Comet

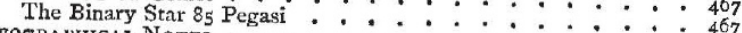

THE FREACH DEEP-SEA ExpIORATION IN THE BAY BF BISCAY By 467 THE FRENCH DEEP-SEA EXPIORATION IN THE BAY OF BISCAY. By
J. GWYN JEFFREYS, LL.D., F.R.S. .

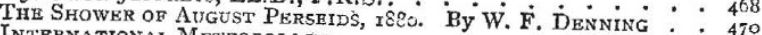

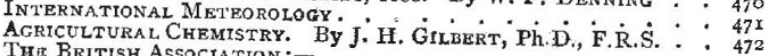
ReITISH Association:-

Reports

Section A-Mathematical and physical. : * . . . . . 47

Section D-Biology $\cdot * \cdot 0^{*} \cdot{ }^{47}$

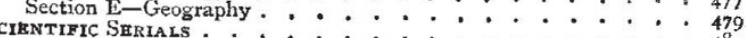

SCIRNTIFIC SHRIAls
SocteTIES AND ACADEMits 